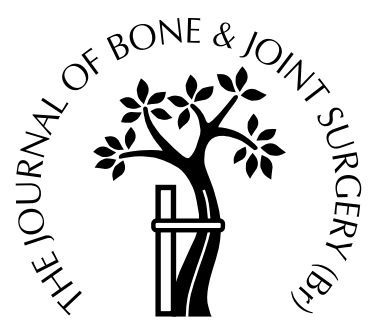

\title{
ULTRASOUND ASSESSMENT AND CONSERVATIVE MANAGEMENT OF INVERSION INJURIES OF THE ANKLE IN CHILDREN
}

\author{
PLASTER OF PARIS VERSUS TUBIGRIP
}

A. P. GLEESON, M. J. STUART, B. WILSON, B. PHILLIPS.
From Booth Hall Children's Hospital, Manchester, England

We studied 45 children who presented with an inversion injury of the ankle. The clinical signs suggested injury to the distal growth plate of the fibula, but the plain radiographs appeared normal. Ultrasound examination of the joint in $\mathbf{4 0}$ patients showed a subperiosteal haematoma consistent with a growth-plate injury in 23 $(57.5 \%)$. Children who had been treated with a tubular bandage and crutches by random selection had a mean time to return of normal activity of $\mathbf{1 4 . 2 2}$ days compared with 21.60 days for those treated with a plaster-of-Paris cast $(t=3.60, p=0.0032 ; d=7.38,95 \%$ CI 3.0 to 11.8).

We conclude that children with inversion ankle injuries who have clinical signs of injury to the distal fibular growth plate but a normal radiological appearance, should be treated with a tubular bandage and crutches.

J Bone Joint Surg [Br] 1996;78-B:484-7.

Received 12 June 1995; Accepted after revision 13 December 1995

Children commonly present with acute inversion injuries of the ankle and a considerable proportion of them show clinical signs of bony injury to the distal fibula; they have local swelling and bony tenderness and are unable to bear weight. When radiographs are normal they are often diagnosed as having a sprain (Heim et al 1990). In children the weakest structure in the skeleton is the growth plate; this is more sus-

A. P. Gleeson, FRCS I, FRCS Ed(A\&E), DA(UK), Accident and Emergency Registrar M.

J. Stuart, FRCS Ed(A\&E), Accident and Emergency Registrar

B. Wilson, FRCR, Consultant Radiologist

B. Phillips, FRCP, Accident and Emergency Consultant

Booth Hall Children's Hospital, Charlestown Road, Blackley, Manchester M9 2AA, UK.

Correspondence should be sent to Mr A. P. Gleeson at the Accident and Emergency Department, the Royal Infirmary of Edinburgh, 1 Lauriston Place, Edinburgh EH3 9YW, UK.

(c)1996 British Editorial Society of Bone and Joint Surgery $0301-620 X / 9631162 \$ 2.00$ ceptible to injury than bone, joint capsule, ligament or tendon (Rang 1969; Rogers 1970). It has therefore been suggested that children with the clinical signs of a fracture of the lower fibula after an inversion injury, but a normal radiograph, may have an undisplaced Salter-Harris I physeal injury (King 1994).

Ultrasound has been shown to be of value in the imaging and diagnosis of skeletal structures including the periosteum around the ankle (Mah et al 1994). We have used it in conjunction with plain radiography to assess inversion injuries of the ankle in children.

Treatment of these injuries has comprised either immobilisation in plaster (POP) because of suspicion of a growthplate injury (King 1994) or merely the use of a supportive bandage and crutches.

We have undertaken a randomised, controlled trial to compare these two forms of treatment.

\section{PATIENTS AND METHODS}

All patients presenting to the Booth Hall Children's Hospital between February and May 1994 were eligible for the study and were selected using an assessment score which included pain (Fig. 1), swelling, growth-plate tenderness and the degree of weight-bearing (Table I). Informed consent was obtained before inclusion in the study. The trial included children who had swelling and tenderness over the lateral malleolus, a normal ankle radiograph with no evidence of growth-plate fusion and who were unable to, or could only partially, bear weight. This corresponded to an assessment score of $\geq 10$.

Initially, there were 51 patients in the series but only 40 had an ultrasound examination and six of these were lost at

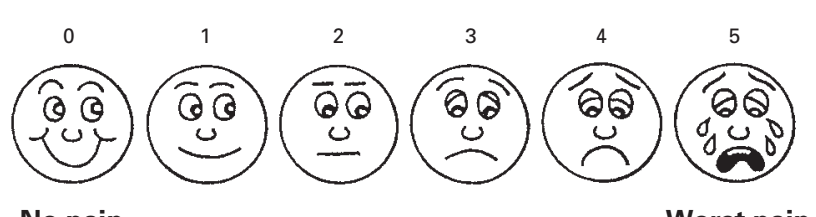

Fig. 1

Visual pain score for a child. 
Table I. Assessment score

\begin{tabular}{ll}
\hline & Score \\
\hline Pain (visual analogue score) & 0 to 5 \\
$\quad$ Swelling & \\
Marked & 4 \\
Moderate & 3 \\
Mild & 2 \\
None & 1 \\
Tenderness & \\
Marked & 4 \\
Moderate & 3 \\
$\quad$ Mild & 2 \\
None & 1 \\
Weight-bearing & \\
None & \\
Partial & 4 \\
Full (some pain) & 3 \\
Full (no pain) & 2 \\
Total & 1 \\
\hline
\end{tabular}

Table II. Ultrasound abnormalities in 40 patients

\begin{tabular}{lcc}
\hline Abnormality & Number & Percentage \\
\hline Soft-tissue swelling & 40 & 100.0 \\
Subperiosteal haematoma & 23 & 57.5 \\
Swelling of peroneus longus & 18 & 45.0 \\
Venous congestion & 3 & 7.5 \\
Joint effusion & 3 & 7.5 \\
Metaphyseal irregularity & 2 & 5.0 \\
\hline
\end{tabular}

follow-up, leaving a total of 45 who completed the study, 34 of whom had ultrasound.

We performed ultrasound examination of the ankle within 72 hours using a $5 \mathrm{MHz}$ high-density linear array probe (ATL Ultramark 9; Advanced Technology Laboratories, Bothell, Seattle). The uninjured ankle was used as a control. The standard view was a coronal section over the lateral aspect of the ankle using a bag of saline as a stand-off medium to bring the structures of interest into the depth of range of the fixed dimensions of focal depth. We studied particularly the lower fibular growth plate and the peroneal tendons; the joint was also examined for evidence of an effusion. We were unable to visualise the lateral ligament complex in sufficient detail to comment on injuries to this structure.

After initial assessment the patients were randomly allocated to management either with a Tubigrip (Seton Healthcare PLC) and crutches or by weight-bearing in a POP cast for two weeks. The Tubigrip group was also given instructions to manage their injury at home by the application of ice and elevation of the limb. The children were seen at two and four weeks and their assessment scores were reviewed. They were questioned as to when they had been able to resume normal activities. The results were analysed using a two-sample t-test.

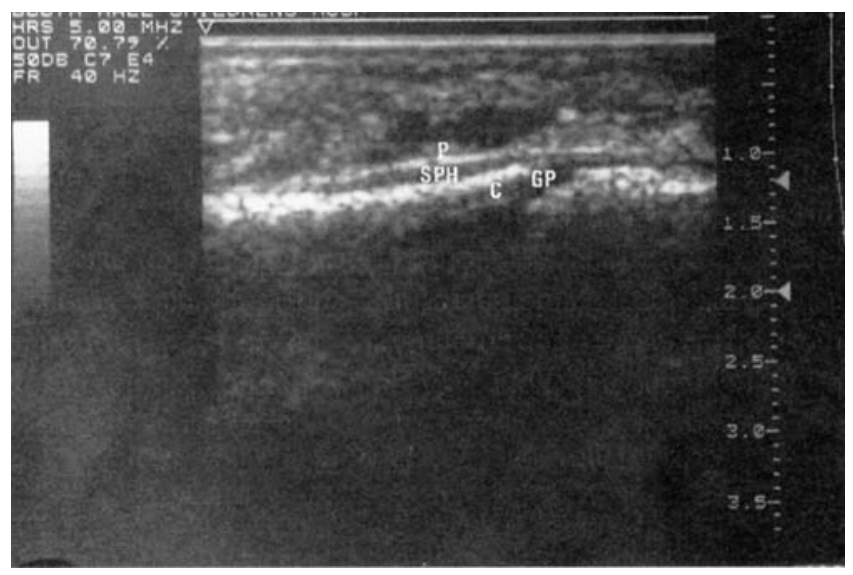

Fig. 2

Coronal section of the lower fibula showing the periosteum $(\mathrm{P})$ detached from the bony cortex (C) with a subperiosteal haematoma (SPH) adjacent to the distal fibular growth plate (GP).

\section{RESULTS}

Ultrasound assessment. We identified the incidence of six abnormalities on the scans (Table II).

Soft-tissue swelling. All patients showed subcutaneous soft-tissue swelling.

Subperiosteal haematoma (Fig. 2). In 23 of the 40 fully assessed patients (57.5\%), the periosteum, seen as a bright echogenic band $(\mathrm{P})$, was detached from the underlying bony cortex (C). The echo-poor area (SPH) between the elevated periosteum and the underlying bony cortex represented a haematoma. Periosteal elevation, when present, was always closely related to the growth plate and extended proximally for a few centimetres.

Swelling of peroneus longus tendon (Fig. 3). The tendon of peroneus longus (PL) was easily seen posteromedial to the lower fibula. Comparisons were made between normal and injured ankles; 18 of the patients $(45 \%)$ showed tendon swelling.

Venous congestion. The tributaries of the short saphenous venous system were dilated in three patients with no visible flow on Doppler examination.

Joint effusion. This was seen in three patients.

Metaphyseal irregularity. Two patients had increased irregularity on the metaphyseal side of the growth plate.

Comparison of management by POP or Tubigrip. In each group patients were matched for age and gender (Table III). The assessment scores of the POP group were marginally higher but the difference was not statistically significant. The POP group had a higher score at two weeks because these patients were unable to bear weight immediately after removal of the cast. The mean time to return of normal activity was 14.17 days in the Tubigrip group compared with 20.19 days in the POP group, which was statistically significant $(t=4.07, p=0.0002 ; d=6.02,95 \%$ CI 3.03 to 


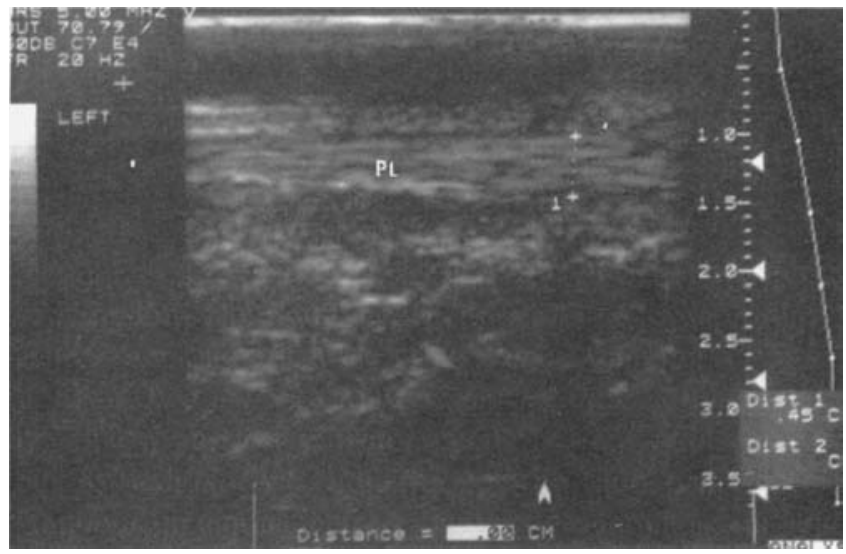

Fig. 3a

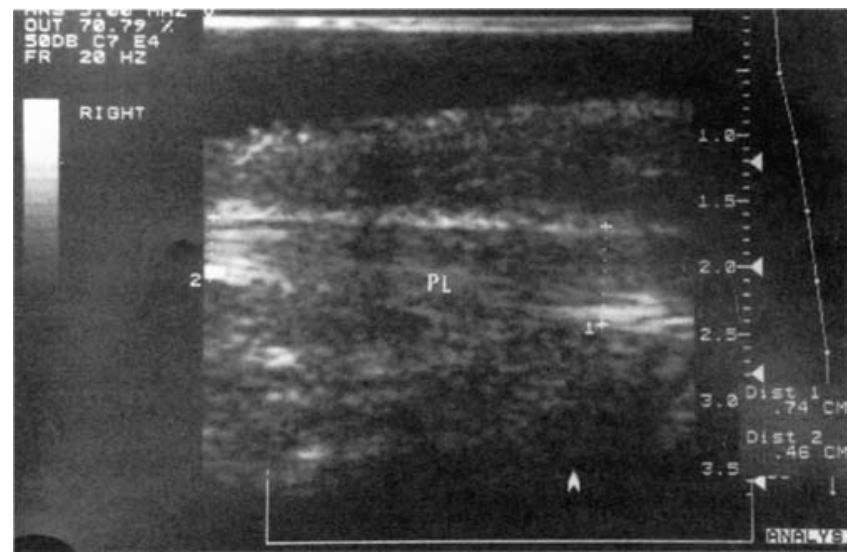

Fig. 3b

Ultrasonograms showing the appearance of the normal peroneus longus (PL) tendon measuring $0.45 \mathrm{~cm}$ (a) and a swollen peroneus longus tendon ( 0.74 $\mathrm{cm})$ at the level of the growth plate (b).

Table III. Details of 45 patients and assessment scores

\begin{tabular}{lccc}
\hline & POP $(\mathbf{n}=\mathbf{2 1})$ & Tubigrip $(\mathbf{n}=\mathbf{2 4})$ & p value \\
\hline $\begin{array}{l}\text { Mean age in years } \\
\text { (range) }\end{array}$ & $9(6$ to 13$)$ & $9.3(3$ to 14$)$ & \\
Male:female & $10: 11$ & $9: 15$ & \\
$\begin{array}{l}\text { Mean assessment score } \\
\text { (range) }\end{array}$ & & \\
$\quad$ & & \\
$\quad$ Day 0 & $13.6(10$ to 17$)$ & $13.2(10$ to 16$)$ & NS \\
$\quad$ Day 14 & $6.3(3$ to 10$)$ & $5.0(3$ to 12$)$ & NS \\
$\quad$ Day 28 & $3.8(3$ to 7$)$ & $3.4(3$ to 7$)$ & NS \\
\hline
\end{tabular}

9.0; Table IV). The 19 children who had definite ultrasound evidence of a growth-plate injury, with or without peroneal swelling, returned to normal activity significantly earlier (14.22 days) when managed with a tubular bandage as opposed to a POP cast ( 21.60 days) $(\mathrm{t}=3.60, \mathrm{p}=0.0032, \mathrm{~d}=$ 7.38, 95\% CI 3.0 to 11.8 ). We obtained similar results in favour of Tubigrip for patients with peroneal swelling and no subperiosteal haematoma, and in those with soft-tissue swelling alone, but the numbers were too small to show statistical significance.

\section{DISCUSSION}

There is debate as to the exact nature of the damage produced by an inversion injury in a young child which causes inability to bear weight, with swelling and tenderness over the lateral malleolus but a normal radiological appearance. An undisplaced Salter-Harris I physeal injury is likely since tears or ruptures of major ligaments are uncommon in childhood, and type-I injuries result from shearing and avulsion forces (Dias and Tachdjian 1978; Boruta et al 1990).

In a child the growth plate is significantly weaker than the joint capsule, ligament or bone, and a force which would produce a ligament sprain in an adult is therefore more likely to result in injury to the growth plate (Rogers 1970). Ligament injuries, however, have been shown to occur in children as a result of ankle inversion (Vahvanen, Westerlund and Nikku 1984). Careful examination of the ankle

Table IV. Mean time in days of return to normal activity in all groups

\begin{tabular}{|c|c|c|c|c|c|}
\hline & $\begin{array}{l}\text { POP } \\
(n=17)\end{array}$ & $\begin{array}{l}\text { Tubigrip } \\
(\mathbf{n}=17)\end{array}$ & d & $95 \% \mathrm{CI}$ & $p$ value \\
\hline \multicolumn{6}{|l|}{ Ultrasound patients $(n=34)$} \\
\hline $\begin{array}{l}\text { Peroneal swelling } \\
\text { (no subperiosteal haematoma) } \\
(\mathrm{n}=6)\end{array}$ & $\begin{array}{l}21.50 \\
(n=2)\end{array}$ & $\begin{array}{l}9.25 \\
(n=4)\end{array}$ & 12.25 & -77.1 to 101.6 & 0.33 \\
\hline $\begin{array}{l}\text { Subperiosteal haematoma } \\
\pm \text { peroneal swelling }(n=19)\end{array}$ & $\begin{array}{l}21.60 \\
(n=10)\end{array}$ & $\begin{array}{l}14.22 \\
(\mathrm{n}=9)\end{array}$ & 7.38 & 3.0 to 11.8 & 0.0032 \\
\hline $\begin{array}{l}\text { Soft-tissue swelling } \\
\text { alone }(n=9)\end{array}$ & $\begin{array}{l}20.20 \\
(n=5)\end{array}$ & $\begin{array}{l}12.25 \\
(n=4)\end{array}$ & 7.95 & 0.5 to 15.4 & 0.04 \\
\hline $\begin{array}{l}\text { All patients } \\
(\mathrm{n}=45)\end{array}$ & $\begin{array}{l}20.19 \\
(n=21)\end{array}$ & $\begin{array}{l}14.17 \\
(n=24)\end{array}$ & 6.02 & 3.03 to 9.0 & 0.0002 \\
\hline
\end{tabular}


may reveal maximal tenderness over the distal fibular epiphysis as opposed to the lateral ligament complex; a second radiograph after two weeks may then show periosteal new bone formation over the adjacent metaphysis (Harris 1981).

In Salter-Harris I fractures the periosteal attachments are usually intact. The epiphysis may be displaced momentarily at the time of the injury, but return to its normal position when the shearing and distracting forces are removed (Salter and Harris 1963). This may detach the periosteum from the cortex adjacent to the growth plate and extend it proximally. The ultrasound appearance of a resulting subperiosteal haematoma was seen in $57.5 \%$ of our patients. The changes seen in the peroneus longus tendon were consistent with a sprain, and any venous congestion was the result of the combined effects of inflammation and dependency.

It has been traditional to use a cast to treat these injuries because of the fear of permanent damage to the growth plate and also to improve comfort. At no time in our study did children treated with a tubular bandage, or their parents, complain of unnecessary discomfort or request immobilisation in plaster.

In a type-I injury the line of cleavage in the growth plate is through the zone of hypertrophic cartilage in which the cells lack the supportive matrix of the other layers (Conrad and Rang 1986). If there is no significant displacement, the epiphyseal vessels which supply the germinal cells will not be disrupted; premature closure of the epiphysis is thus unlikely to occur.

No benefits in any form have been received or will be received from a commercial party related directly or indirectly to the subject of this article.

\section{References}

Boruta PM, Bishop JO, Braly WG, Tullos HS. Acute lateral ankle injuries: a literature review. Foot Ankle 1990;11:107-13.

Conrad KU, Rang MC. Fractures and sprains. Pediatr Clin North Am 1986;33:1523-40.

Dias LS, Tachdjian MO. Physeal injuries of the ankle in children: classification. Clin Orthop 1978;136:230-3.

Harris EJ. Epiphyseal plate injuries in paediatric ankle traumatology. $J$ Foot Surg 1981;20:145-7.

Heim M, Blankstein A, Israeli A, Horoszowski H. Which X-ray views are required in juvenile ankle trauma?. Arch Orthop Trauma Surg 1990;109:175-6.

King JB. ABC of sports medicine: management of the acutely injured joint. BMJ 1994;309:46-9.

Mah ET, LeQuesne GW, Gent RJ, Paterson DC. Ultrasonic features of acute osteomyelitis in children. J Bone Joint Surg [Br] 1994;76-B:96974.

Rang M, ed. The growth plate and its disorders. Edinburgh: E \& S Livingstone Ltd, 1969.

Rogers LF. The radiography of epiphyseal injuries. Radiology 1970;96:289-99.

Salter RB, Harris WR. Injuries involving the epiphyseal plate. $J$ Bone Joint Surg [Am] 1963;45-A:587-622.

Vahvanen V, Westerlund M, Nikku R. Lateral ligament injury of the ankle in children: follow-up results of primary surgical treatment. Acta Orthop Scand 1984;55:21-5. 